\title{
Injury, Serum Lipids, Fat Embolism, and Clofibrate
}

\author{
M. O’DRISCOLL, ${ }^{*}$ F.R.C.S. ; F. J. POWELL, $†$ M.SC., A.R.I.C.
}

Brit. med.F., 1967, 4, 149-151

The mechanism of fat embolism following injury has excited much controversy since it was first described by Zenker in 1862 . Two theories seek to explain it-the classical mechanical theory, which is supported by Sevitt (1962), and the metabolic theory, which is supported by Evarts (1965). The mechanical theory suggests that following trauma fat is liberated from the marrow cavity into the venous sinusoids, whence it passes in the form of globules into the systemic circulation. The metabolic theory suggests that tissue injury may initiate changes in the physiochemical state of the blood, and that this alters the emulsion stability of the blood lipids. Together with the activation of a lipid-mobilizing hormone by trauma this results in the formation of fat globules.

Fat embolism follows trauma (usually to bones). There is a lucid interval of variable duration and then signs of respiratory and systemic fat embolism develop, together with changes in the mental state and level of consciousness; a petechial rash also occurs on the head, neck, and thorax.

In this study, firstly, an attempt was made to try to establish whether there was any change in the serum non-cholesterol lipids after trauma; secondly, the incidence of all degrees of the syndrome of fat embolism was investigated; and, thirdly, the effect of Atromid (clofibrate) on the serum lipids and the incidence of fat embolism was studied. Clofibrate was used because it has an effect on the lipids of the hyperlipaemic patient and has also been found to depress postprandial lipaemia.

\section{Material and Methods}

The patients were inmates of the orthopaedic unit at St. James's Hospital, Leeds, either as a result of injury serious enough to warrant admission or because they were undergoing orthopaedic surgery. They were divided into two groups (Table I). One group received standard therapy, and the other received clofibrate as well, as soon as they were able to take capsules. The dosage of clofibrate used was $750 \mathrm{mg}$. by mouth followed by $500 \mathrm{mg}$. six-hourly for two days, then $250 \mathrm{mg}$. six-hourly for three days, then $250 \mathrm{mg}$. twice daily for two days, and finally $250 \mathrm{mg}$. daily for two days. The dose was tailed off to prevent any rebound effects. Eight patients who had had operations on non-bony structures also received clofibrate.

\section{Laboratory Estimations}

Plasma total lipids were estimated by the rapid turbimetric method of Kunkel et al. (1948), giving normal ranges between 340 and $640 \mathrm{mg} . / 100 \mathrm{ml}$. and a $5 \%$ error against standard sera. Cholesterol levels were measured by the method of Carr and Drekter (1956) on the first 30 samples and subsequently by direct estimation on an autoanalyser (Kenny and Jamieson, 1963). Cholesterol levels were then subtracted from the total levels to give the non-cholesterol lipid levels.

Sputum was examined for fat globules by adding scharlach $\mathrm{R}$ and then by direct microscopy. Urine (end samples) were examined by centrifugation for five minutes, adding scharlach $\mathrm{R}$ to the deposit, and then by direct microscopy. Specimens of

* Orthopaedic Registrar, Central Middlesex Hospital, London N.W.10. † Head Biochemist, St. James's Hospital, Leeds 9.

sputum from 10 patients with chronic bronchitis in acute exacerbation and samples of urine from six patients with prostatic hypertrophy and urinary infection were examined as controls.

Blood was drawn from an arm vein, with tourniquet, of all patients on arrival in the casualty department, or immediately preoperatively in patients undergoing orthopaedic operations.

TABLB I.-Patients in the Series and Injuries Sustained

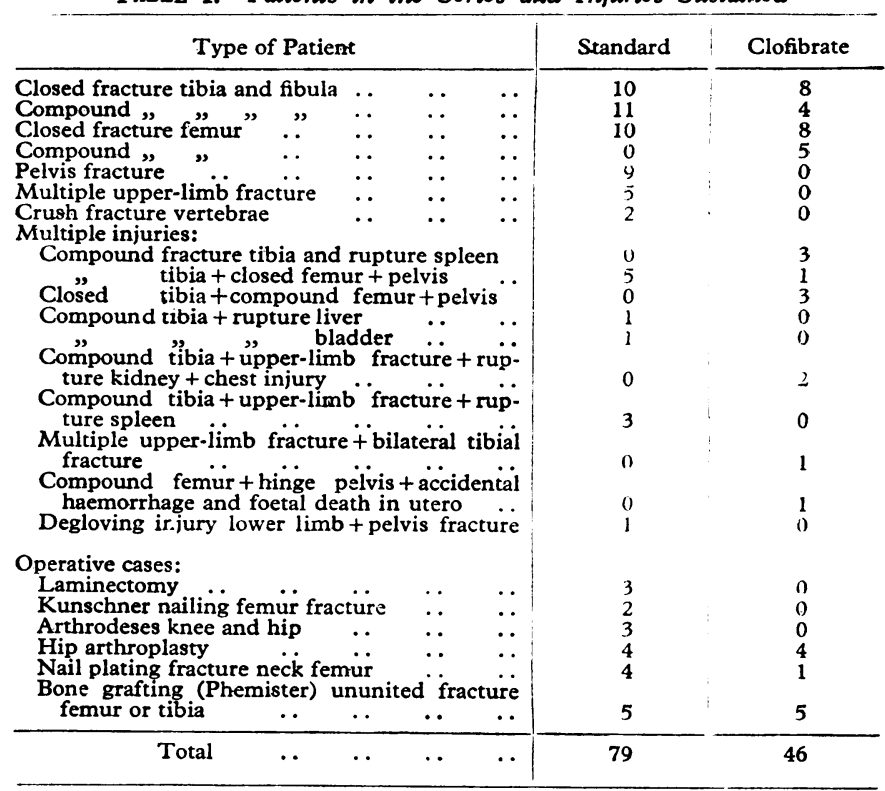

Further samples were taken on the next five or six days, with the patients fasting. Blood was also drawn from the femoral vein of the injured limb in nine patients with fractures of the leg-before, during, and after manipulation, when the patients were anaesthetized for the manipulation.

\section{Clinical Examination}

Features noted were (a) mental and conscious state ; $(b)$ skin and conjunctivae for petechiae ; $(c)$ the results of chest examination, particularly for central rales and other signs of pulmonary oedema (radiography being performed on the slightest evidence of abnormality and the $x$-ray film being compared with the earlier chest $x$-ray film); (d) neurological examination ; and $(e)$ pulse and respiration rate and any signs of so-called "fracture fever."

Necropsy was carried out on the patients who died.

TABLB II

Major Fat Embolism a) Post-mortem findings of fat embolism

(b) Petechial rash coma

(d) Respiratory insufficiency with snowstorm chest $x$-ray change, which must be bilatera

$$
\begin{aligned}
& \text { (a) Fat globules in sputum } \\
& \text { (b) Haemoptysis } \\
& \text { (c) Signs of central pulmonary oedem. } \\
& \text { (d) Chest radiographic change of mi } 1 \text { - } \\
& \text { zone mottling, patchy consolida- } \\
& \text { tion-which must be bilateral } \\
& \text { (e) Fat globules found in end samples o: } \\
& \text { urine }
\end{aligned}
$$


Though the florid syndrome of fat embolism is easy to diagnose, many subclinical cases occur, with few if any of the classical signs, and may be diagnosed only by chest radiography (Berrigan et al., 1966). We have therefore classified our patients into two groups (Table II).

To make the diagnosis of fat embolism we required one major plus one minor criterion, or three or more minor criteria, of which one had to be the presence of changes in the chest radiograph.

\section{Resuits}

\section{Serum Lipids}

Daily estimation of the serum non-cholesterol lipid levels showed minimal or no deviation from the normal on any of the six days after operation in the control group ; graphs were plotted of the lipid levels of all the subjects: Fig. 1 shows that in those not receiving clofibrate there was an appreciable rise

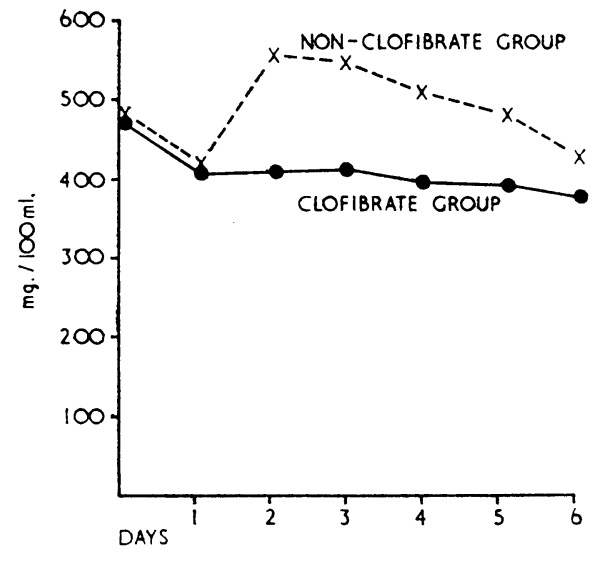

Fig. 1 such samples were taken from each patient, as well as from an arm vein. The results (Table III) show a surprising uniformity, the values in the femoral vein samples comparing well with those in the arm vein samples; we were unable to demonstrate the existence of a shower of fat globules from the fracture sites.

\section{Fat in Sputum and Urine}

Among the group of 79 patients who did not receive clofibrate we found fat globules in the sputum of 30 in amounts varying from scanty to profuse. Of the 46 treated with clofibrate three showed fat in their sputum. No fat was seen in the control group of 10 bronchitics. The maximum number of patients developed fat in their sputa on the third day-14 in the nonclofibrate group and two in the group treated with clofibrate.

The presence of fat in the urine was found to be an unreliable index of fat embolism. Three patients died of fat embolism, proved at necropsy, and none of these had fat in their urine at

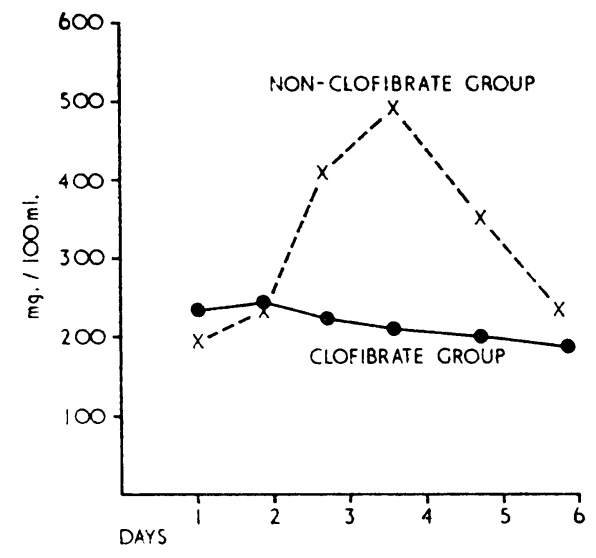

Fig. 2

FIg. 1.-Serum lipids of total cases. FIG. 2.-Serum lipids of patients on clofibrate for one procedure and not for another.

to the third and fourth days, which fell off slowly. In the patients receiving clofibrate, on the other hand, lipid levels did not rise. The difference was statistically significant. Moreover, when the seriously injured patients were considered separately the difference in lipaemia between those receiving clofibrate and those not was even more apparent. This difference was noted again in seven patients, each of whom underwent two operative procedures of comparable severity, one being covered by treatment with clofibrate and the other not (Fig. 2).

Samples of blood were obtained from the femoral vein in nine patients, of whom four had closed fractures of the femoral shaft, three had closed fractures of the tibia and fibula, and two had compound fractures of the tibia and fibula. The samples were taken with wide-bore needles from the vein of the affected limb, high up against the inguinal ligament to catch blood issuing from the profunda femoris vein as well. Three

\begin{tabular}{|c|c|c|c|c|}
\hline \multirow[b]{2}{*}{ Injury } & \multicolumn{4}{|c|}{ Serum Lipids (mg. $/ 100 \mathrm{ml}$.) } \\
\hline & Arm Vein & $\begin{array}{c}\begin{array}{c}\text { Femoral } \\
\text { Vein, Pre- } \\
\text { manipulation }\end{array} \\
\end{array}$ & \begin{tabular}{c|} 
Femoral \\
Vein During \\
Manipulation
\end{tabular} & $\begin{array}{l}\text { Femoral } \\
\text { Vein. Post- } \\
\text { manipulation }\end{array}$ \\
\hline $\begin{array}{l}\text { Femur fracture } \\
\text { (closed) }\end{array}$ & $\begin{array}{l}170 \\
500 \\
857 \\
515\end{array}$ & $\begin{array}{l}160 \\
500 \\
857 \\
494\end{array}$ & $\begin{array}{l}120 \\
500 \\
744 \\
494\end{array}$ & $\begin{array}{l}120 \\
490 \\
800 \\
510\end{array}$ \\
\hline $\begin{array}{l}\text { Tibia and fibula } \\
\text { fracture } \\
\text { (closed) }\end{array}$ & $\begin{array}{l}686 \\
770 \\
445\end{array}$ & $\begin{array}{l}695 \\
725 \\
415\end{array}$ & $\begin{array}{l}686 \\
720 \\
410\end{array}$ & $\begin{array}{l}686 \\
700 \\
387\end{array}$ \\
\hline $\begin{array}{l}\text { Tibia and fibula } \\
\text { fracture } \\
\text { (compound) }\end{array}$ & $\begin{array}{l}214 \\
528\end{array}$ & $\begin{array}{l}208 \\
479\end{array}$ & $\begin{array}{l}195 \\
429\end{array}$ & $\begin{array}{l}190 \\
460\end{array}$ \\
\hline
\end{tabular}

any stage. Of the total of 125 patients, seven were found to have fat in their urine, and it did not appear until the fourth day.

Of the patients who did not receive clofibrate, 30 had chest signs, usually in the mid-zone, or raised respiratory and pulse rates, or haemoptysis, or combinations of these. Pleuritic pain, usually left-sided, was also noted in eight cases. Of the clofibrate-treated patients three had fat in their sputum, increased respiratory and pulse rate, and rales; one patient also had pleuritic pain. Of the patients with abnormal chest signs and fat in the sputum, 27 had chest $x$-ray changes compatible with pulmonary oedema. No patients treated with clofibrate had chest $x$-ray changes.

The presence of a petechial rash was looked for in a good light. It was found in seven patients of the non-clofibrate group (five of whom also had confusion and marked chest $x$-ray changes). Nevertheless, the rash was not present in one patient who died of fat embolism. None of the clofibratetreated patients developed a rash.

Coma, which carries a grave prognostic sign in fat embolism, occurred in one patient in the non-clofibrate group after a lucid interval of 24 hours. Four other patients became very confused, requiring sedation for several days, and becoming normal again only after several weeks. Two of these patients had temporary loss of sphincter control.

Six patients died in the non-clofibrate group (three from fat embolism), and none in the clofibrate group.

Stainable fat globules in sputum are thought significant of fat embolism (Robb-Smith, 1941). 


\section{Diagnosis of Fat Embolism}

The diagnosis was made by using our system of criteria. In the non-clofibrate group three had fat in the sputum and chest signs, but no $x$-ray changes, so were not thought to have fat embolism. Twenty-seven other patients had either one or more major signs, or three or more minor signs, with $x$-ray changes, and hence were thought to have fat embolism.

A careful note was made of the day on which the features of fat embolism were sufficient to warrant diagnosis ; from Day 1 to Day 6 the numbers of cases were $2,7,13,4,1$, and 0 respectively. These figures corresponded with the distribution of the maximum serum-lipid concentration (Fig. 3).

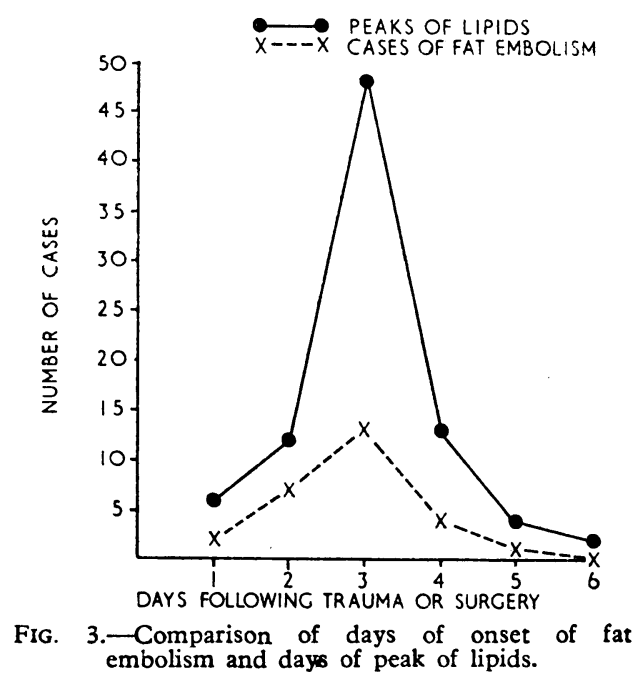

\section{Illustrative Case}

A youth aged 19 was involved in a motor-cycle crash. He was not knocked out, but on admission was clinically shocked though fully conscious and alert. He had sustained a compound fracture of the mid-shaft of the right femur, a compound fracture of the right patella penetrating the knee joint, and a compound fracture of his right tibia and fibula. He needed a transfusion of 3 pints (1.7 1.) of blood before he was fit enough for wound toilet, patellectomy, and manipulation of the fractures-which were done under general anaesthesia, the fractures being immobilized on a Thompson splint and using plaster-of-Paris. Postoperatively he remained well for 24 hours, after which he became confused and comatose within three hours. Fat embolism was diagnosed in view of the history of injury; the absence of signs of intercranial haemorrhage, the presence of rales, and a petechial rash on examination; and the appearances suggesting pulmonary oedema on chest $x$-ray film. He also developed ankle clonus, a raised pulse rate, and a temperature of $100^{\circ} \mathrm{F}$. $\left(37.8^{\circ} \mathrm{C}\right.$.).

He was treated with intermittent positive-pressure respiration and hypothermia. For five days he made some improvement on this regimen, but deterioration occurred and he died on the sixth day after injury. Necropsy showed gross petechial haemorrhages throughout the brain, particularly in the pons and medulla, and, histologically, intracapillary fat globules were present in the brain and in the lung vessels.

\section{Discussion}

Much evidence shows that fat embolism is not entirely due to fat getting into the circulation mechanically. The existence of lipaemia after trauma was demonstrated as long ago as 1921 (Bloor, 1921). Johnson and Svanborg (1956) and Bergentz (1961) have demonstrated this in animals, while Gottlieb (1964) has described this in patients who did not have a fracture.
We have shown that a definite lipaemia exists after injury or operation to bone, which rises to a maximum three to four days later and then falls off fairly rapidly. The degree of lipaemia was found to have no relation to the occurrence of fat embolism, but in those patients who had some degree of fat embolism it was at least double the earliest concentration determined. On the other hand, there was a definite correlation between the peak of the lipaemia and the onset of signs of fat embolism. The incidence of clinically recognizable fat embolism was high in the non-clofibrate group ( $34.2 \%)$, and there were three deaths $(3.75 \%$ ) - a figure which agrees with other series (Sevitt, 1962 ; Evarts, 1965). In the clofibrate group, on the other hand, there were only two cases $(4.3 \%)$, and no deaths occurred.

Since clofibrate appears to have diminished both lipaemia and fat embolism, it is logical to suggest that the relation between the last two may be causal. Barrett (quoted by Thorpe, 1962) believes that clofibrate acts by virtue of its affinity for serum albumin, resulting in the reduction of the adrenaline-stimulated release of free fatty acids from the fat stores. This in its turn suggests that adrenaline may be implicated in the pathogenesis of fat embolism. Baur and Ludin (1950) found that irradiation of the spine of patients with ankylosing spondylitis caused a rise in the serum histamine concentration as a result of bonemarrow damage. Histamine is known to mobilize adrenaline, and this further mobilizes fat from fat depots. Since bone marrow is damaged by trauma, this could be a possible sequence leading eventually to fat embolism.

A further point in favour of a metabolic cause for fat embolism is our finding on the femoral vein samples. In none of these samples were we able to demonstrate the presence of a shower of fat; in fact, if anything the fat levels in blood draining from the injured limb were lower than those in concomitantly taken arm vein samples.

\section{Summary}

A significant lipaemia was found in 79 patients who were followed for a period of six days after trauma, and corresponded at its peak to the onset of fat embolism. There were 27 patients with some degree of fat embolism, three of whom died. A series of 46 patients with bone injury were treated with clofibrate. Lipaemia was substantially reduced and only two instances of fat embolism occurred.

We would like to thank Mr. R. Broomhead, Mr. J. M. Fitton, and Mr. F. W. Shea, orthopaedic surgeons, St. James's Hospital, Leeds ; Dr. J. Goldie and the staff of the pathology department, St. James's Hospital, Leeds ; Mr. J. M. O'Mahoney and Mr. D. Macwilliams ; Mr. J. G. Bonin and Mr. A. J. Howse, of the orthopaedic unit, the Central Middlesex Hospital, London; and Dr. S. L. Lewis for their help.

\section{REFERENCES}

Baur and Ludin, M. (1950). Quoted by A. Böni and G. Kaganas, Documenta Rheumatologica (Geigy), 1954, No. 3, p. 48.

Bergentz, S. E. (1961). Acta chir. scand., Suppl. No. 282.

Berrigan, T. J., Carsky, E. W., and Heitzman, E. R. (1966). Amer. F. Roentgenol., 96, 967.

Bloor, W. R. (1921). F. biol. Chem., 49, 201.

Carr, J. J., and Drekter, I. J. (1956). Clin. Chem., 2, 353.

Evarts, C. M. (1965). F. Amer. med. Ass., 194, 899.

Gottlieb, L. H. (1964). Hawaii med. F., 24, 30. Quoted in Therapeutic Notes, 1966, 6, 150.

Johnson, S. R., and Svanborg, A. (1956). Ann. Surg., 144, 145.

Kenny, A. P., and Jamieson. A. J. (1963). Proc. Ass. clin. Biochemists, $2,213$.

Kunkel, H. G., Ahrens, E. H., and Eisenmenger, W. J. (1948). Gastroenterolozy, 11, 499.

Robb-Smith, A. H. T. (1941). Lancet, 1, 135.

Sevitt, S. (1962). Fat Embolism. London.

Thorpe, J. M. (1962). Lancet, 1, 1323.

Zenker, F. A. (1862). Quoted by S. Sevitt, Fat Embolism, p. 2. London. 